\title{
Taking the stage: a development programme for women speakers in emergency medicine
}

\author{
Kharmene L Sunga, ${ }^{1}$ Dara Kass ${ }^{2}$
}

\begin{abstract}
- Additional material is published online only. To view please visit the journal online (http://dx.doi.org/10.1136/ emermed-2018-207818).

${ }^{1}$ Department of Emergency Medicine, Mayo Clinic, Rochester, Minnesota, USA ${ }^{2}$ Department of Emergency Medicine, Columbia University Medical Center, New York City, New York, USA
\end{abstract}

\section{Correspondence to}

Dr Kharmene L Sunga, Department of Emergency Medicine, Mayo Clinic, Rochester, Minnesota 55905 , USA;

Sunga.Kharmene@mayo.edu

Received 21 May 2018 Revised 12 November 2018 Accepted 15 December 2018 Published Online First 10 January 2019

\section{Check for updates}

(C) Author(s) (or their employer(s)) 2019. No commercial re-use. See rights and permissions. Published by BMJ.

\section{ABSTRACT}

Female physicians in the USA achieve associate and full professor rank at numbers disparate to their representation within emergency medicine (EM). The authors describe a novel curriculum aimed at developing women speakers as a step on the journey towards academic recognition. In this pilot programme, four female physicians at a single academic emergency department participated in a year-long Speaker Development Programme (SDP), and all presented in at least one national EM conference at SDP completion. Participants reported improved speaking skills, confidence and drive to present externally. Elements to success were mentor engagement, encouragement by the departmental chair and creation of a growth and belonging mindset within the cohort. Future steps include creating a framework for maintaining the SDP beyond the pilot phase, such as ensuring access to curriculum materials, and retaining an experienced external mentor over time.

\section{BACKGROUND}

Female physicians working in emergency medicine (EM) in the USA comprise $33 \%$ of full-time faculty, yet account for only $24 \%$ of associate professors and $17 \%$ of full professors. ${ }^{1}$ Although criteria vary regarding academic promotion from instructor to full professor, the process rewards individuals who have demonstrated expertise, such as through invited extradepartmental speaking engagements. A recent study demonstrated that only $29.9 \%$ of presentations at six major national (Australia, Canada, USA) and two international EM conferences were given by women. ${ }^{2}$ Perceptions of speaking inexperience and lack of 'qualification' are cited as reasons why women are invited to speak less often. ${ }^{3}$ This novel combined self-directed/ mentorship-based curriculum aims to address these perceptions.

\section{THE PROGRAMME}

The intervention was proposed as a year-long Speaker Development Programme (SDP) by one of the authors (DK), during an academic innovations session at the 2016 Society for Academic EM (SAEM) Annual Meeting. The Chair of the Department of EM, Mayo Clinic, Rochester, Minnesota, committed to her faculty participating. DK selected the external mentor, a highly regarded speaker from another medical school.

\section{Implementation}

As the departmental Diversity Chair, one of the authors (KS) was tasked with participant

\section{Key messages}

What is already known on this subject

- Female physicians in the USA achieve associate and full professor rank at numbers disparate to their representation within emergency medicine (EM). Recent recommendations supporting the careers of women in EM emphasise strategic mentorship and opportunities for faculty development.

\section{What this study adds}

- The Speaker Development Programme (SDP) is a year-long curriculum consisting of three phases involving (1) self-directed learning on presentation theory, (2) video recorded presentation delivery followed by group feedback sessions involving the SDP cohort and an external mentor and (3) subsequent refinement and delivery of presentations in an external setting. Participants reported improved speaking skills, confidence and drive to present externally.

recruitment, liaising with the SDP external mentor, coordinating departmental conference presentations and facilitating cohort video feedback sessions. The project was deemed exempt from review by the Mayo Clinic Institutional Review Board.

\section{Recruitment}

The initial cohort was limited to four participants in consideration of potential scheduling difficulties. Recruitment was based on leadership roles and/or research experience, and intentionally diverse with regard to career stage and presentation portfolio, as female faculty at all stages could benefit from the women-specific focus (table 1). Participation was voluntary, although all accepted after reviewing the proposal. Participants received no compensation for their time.

\section{Protocol}

At the start of the SDP, KS and the chair held an overview session with participants clarifying immediate and long-term goals of the programme: (1) enhancing skills and confidence in presentation abilities and (2) raising academic profiles through external speaking engagements.

In Phase 1, participants completed self-directed book and free open access medical education (FOAMed) video learning assignments on 
Table 1 Speaker Development Programme participant characteristics at recruitment (June 2016)

\begin{tabular}{llllll}
\hline $\begin{array}{l}\text { Participant } \\
\text { identifier }\end{array}$ & $\begin{array}{l}\text { Years since } \\
\text { residency } \\
\text { graduation }\end{array}$ & $\begin{array}{l}\text { Peer- } \\
\text { reviewed } \\
\text { articles }\end{array}$ & $\begin{array}{l}\text { Regional } \\
\text { presentations }\end{array}$ & $\begin{array}{l}\text { National } \\
\text { presentations }\end{array}$ & $\begin{array}{l}\text { International } \\
\text { presentations }\end{array}$ \\
\hline A & 3.7 & 4 & 1 & 1 & 0 \\
B & 3.7 & 79 & 6 & 6 & 8 \\
C & 4 & 2 & 1 & 0 & 0 \\
D & 9 & 41 & 2 & 3 & 0 \\
\hline
\end{tabular}

presentation theory (online supplementary file) over 4 weeks between August and September 2016.

In Phase 2, participants independently created and then individually delivered their presentations at departmental Grand Rounds. All presentations were video recorded. There were two video chat feedback sessions scheduled-one in February 2017 to review two of the participants' presentations and the other in June 2017 for the other two participants. The external mentor, $\mathrm{KS}$ and the participant cohort all reviewed the video recordings before the sessions. The external mentor asked participants to perform a general self-critique and then provided detailed feedback focused on slide design, presentation content and flow, speaking style, appearance and body language. The cohort was allowed to provide additional input, and participants were given time to ask clarifying questions for presentation improvement.

In Phase 3, participants submitted and delivered lectures in any external setting. All of the participants were successful in presenting in at least one national EM conference by September 2017.

\section{Outcomes}

Of the required study materials, most participants preferred the Talk Like TED (Gallo, 2014) book and 'Powerpoints and Meth' (Weingart, 2016) video (online supplementary file). Participant reactions to the SDP were positive and are presented in box 1 .

\section{DISCUSSION}

Previous authors have suggested there are potentially several reasons for gender disparity in academic medicine. Women may place lower value on workplace aspirations versus men. ${ }^{4}$ Women may volunteer for fewer opportunities due to feeling inadequate or unqualified. ${ }^{56}$ Women may also not apply for promotion due to lack of encouragement. ${ }^{7}$ Recent recommendations supporting the careers of women in EM emphasise the need for strategic mentorship and opportunities for faculty development. ${ }^{8}$ We believe the SDP was in part successful due to intentional focus on these recommendations. While we cannot determine longterm effects of the programme on participants' academic careers, our outcomes suggest the SDP can improve women physician's self-confidence and presentation skills.

Cultivating a growth mindset (aspiring to a continual state of reflection and improvement) and a belonging mindset (witnessing involvement of others similar to oneself) within academic departments may improve motivation and close gender gaps. ${ }^{9}$ Early during the SDP, the department chair provided career context with regard to academic rank. As reflected in SDP participant comments, the peer group format was well-received. It is notable that one participant with extensive presentation experience following a research fellowship still found the programme useful for her presentation skills. Another participant who had fewer speaking engagements than might be expected given her research profile stated that this programme would likely influence her to accept speaking invitations in the future.
Box 1 Participant (A-D) and department chair (E) reactions to the Speaker Development Programme (gathered May/June 2017)

A. 'I think this programme is incredible and would highly recommend it to others looking to become more comfortable with speaking. I think my lecture style was boring and I didn't realise it because that's how most others lecture as wellafter seeing so many great talks both from the participants in this group and in the lectures we watched through the programme, I've realised how little I knew about this. I'm not sure what my style is now, but I am much more aware of the content I choose [to] deliver and the way it is presented. I feel much more confident-I have a number of speaking events this year and I feel well prepared.'

B. 'Hadn't [thought] much about [my lecture skill and style] before the programme. I feel comfortable speaking but I am not a good speaker as I think I a[m] a bit boring to hear and do not engage the audience. After completing the programme I think my skills have improved. It helped a lot to watch myself [on] video. It [came] at a perfect time, as I am giving six other lectures this year, including five international.'

C. 'I have absolutely loved and appreciated the programme so much. Not just because I have improved as a speaker but also because it is a wonderful feeling to be invested in! My perception of lecture skill/style: Before programme: I had given little thought to my 'skill or style'. I tried to create interesting slides but when I needed to get information across I relied on word-rich slide formatting. Since the programme: I think my style is to[o] related emotionally and I have become more focused (than before) in setting goals for my talk. This has increased my confidence to speak regarding topics of interest and to reach out to outside of Mayo organisations.'

D. 'My skills and style definitely improved. I feel much more confident. It improved my Grand Rounds and has helped me to more effectively help my mentees and will make me more likely to accept speaking invitations.'

E. 'From my perspective, the speakers' development programme has been a wonderful addition to our faculty development efforts. It has allowed me to develop the academic careers of a small group of early to mid career female faculty members with intention. The outcomes of the programme have been absolutely wonderful to witness. I have noticed incredible differences in message selection, slide making abilities, speaking abilities, and their confidence with public speaking. Additionally, the cohort of participants now serves as a wonderful peer-mentoring group for one another and for other non-participant faculty members. While the programme was intended to improve the speaking abilities of female faculty members, I am confident that all faculty members will benefit from the quorum of expertise which is a byproduct of the programme. This was one of the very best investments I have made as a Chair, as the R[eturn] O[n] I[nvestment] was huge.'

We believe this programme was successful because of chair support, peer engagement, external accountability and facilitation of the project by a departmental champion. We anticipate that SDP 'graduates' will share their skills with future mentees, creating growth opportunities for both women and men down the line. 
We hope that other departments will consider implementing an SDP. Next steps include developing a framework for SDP maintenance, such as identifying additional high-quality videos on presentation theory, as several of the FOAMed videos used in Phase 1 are no longer available (online supplementary file). This is an expected complication when using free open access materials. We recommend small cohort numbers to minimise scheduling challenges. The programme we conducted was inexpensive, as books purchased by the department can be redirected towards future participants. However, an important step would be to recruit and retain an experienced external mentor. The mentor in this pilot received no compensation for his time during our pilot, but the donation of time by some of our busiest academicians is not a strong foundation for sustaining an educational programme.

\section{CONCLUSION}

A programme aimed at bolstering the skills and confidence of women speakers in academic EM has been described. Participants found the programme successful and reported an increased drive to present at external conferences. Key elements to success were mentor engagement, departmental chair support and creation of growth and belonging mindsets within the cohort.

Acknowledgements The authors would like to thank Dr. Annie Sadosty for

Funding The authors have not declared a specific grant for this research from any funding agency in the public, commercial or not-for-profit sectors.
Competing interests DK is the editor-in-chief of the FemInEM website and received a monetary prize from SAEM after acceptance of the SDP proposal at the 2016 Annual Meeting.

Patient consent Not required.

Ethics approval The study was deemed exempt from review by the Mayo Clinic Institutional Review Board.

Provenance and peer review Not commissioned; externally peer reviewed.

\section{REFERENCES}

1 Association of American Medical Colleges website. The state of women in academic medicine: the pipeline and pathways to leadership 2015-16 - table 4a: distribution of full-time women md faculty by Department and Rank. 2015 https://www.aamc.org/ download/481184/data/2015table4a.pdf (accessed 21 Mar 2018).

2 Carley S, Carden R, Riley R, et al. Are there too few women presenting at emergency medicine conferences? Emerg Med J 2016;33:681-3.

3 Klein RS, Voskuhl R, Segal BM, et al. Speaking out about gender imbalance in invited speakers improves diversity. Nat Immunol 2017;18:475-8.

4 Thibault GE. Women in academic medicine. Acad Med 2016;91:1045-6.

5 Ehrlinger J, Dunning D. How chronic self-views influence (and potentially mislead) estimates of performance. J Pers Soc Psychol 2003;84:5-17.

6 Kay K, Shipman C. The confidence gap. https://www.theatlantic.com/magazine/archive/ 2014/05/the-confidence-gap/359815/ (accessed 21 Mar 2018).

7 Paulus JK, Switkowski KM, Allison GM, et al. Where is the leak in the pipeline? Investigating gender differences in academic promotion at an academic medical centre. Perspect Med Educ 2016;5:125-8.

8 Choo EK, Kass D, Westergaard M, et al. The development of best practice recommendations to support the hiring, recruitment, and advancement of women physicians in emergency medicine. Acad Emerg Med 2016;23:1203-9.

9 Rattan A, Savani K, Chugh D, et al. Leveraging mindsets to promote academic achievement: policy recommendations. Perspect Psychol Sci 2015;10:721-6. 